\title{
Towards Understanding Excited-State Properties of Organic Molecules Using Time-Resolved Soft X-ray Absorption Spectroscopy
}

\author{
Holger Stiel 1,2,*, Julia Braenzel 1,2, Adrian Jonas 1,3, Richard Gnewkow 1,3,4, Lisa Theresa Glöggler 1,3,+, \\ Denny Sommer ${ }^{2}$, Thomas Krist ${ }^{5}$, Alexei Erko ${ }^{6}$, Johannes Tümmler ${ }^{1,2}$ and Ioanna Mantouvalou ${ }^{1,3,4}$ (D) \\ 1 Berlin Laboratory for Innovative X-ray Technologies (BLiX), D-10623 Berlin, Germany; \\ braenzel@mbi-berlin.de (J.B.); A.Jonas@tu-berlin.de (A.J.); richard.gnewkow@googlemail.com (R.G.); \\ lisa.gloeggler@mailbox.tu-berlin.de (L.T.G.); tuemmler@mbi-berlin.de (J.T.); \\ ioanna.mantouvalou@helmholtz-berlin.de (I.M.) \\ 2 Max-Born-Institut für Nichtlineare Optik und Kurzzeitspektroskopie, D-12489 Berlin, Germany; \\ Denny.Sommer@mbi-berlin.de \\ Analytical X-ray Physics, TU Berlin, D-10623 Berlin, Germany \\ 4 Helmholtz Zentrum Berlin, D-12489 Berlin, Germany \\ NOB Nano Optics Berlin GmbH, D-10627 Berlin, Germany; info@nanooptics-berlin.com \\ $6 \quad$ IAP eV, D-12489 Berlin, Germany; erko@iap-adlershof.de \\ * Correspondence: stiel@mbi-berlin.de \\ † Current address: Physics Department, CERN, 1211 Geneva, Switzerland.
}

Citation: Stiel, H.; Braenzel, J.; Jonas, A.; Gnewkow, R.; Glöggler, L.T.; Sommer, D.; Krist, T.; Erko, A.; Tümmler, J.; Mantouvalou, I. Towards Understanding Excited-State Properties of Organic Molecules Using Time-Resolved Soft X-ray Absorption Spectroscopy. Int. J. Mol. Sci. 2021, 22, 13463. https://doi.org/ $10.3390 /$ ijms 222413463

Academic Editors: Dieter Leupold and Hugo Scheer

Received: 5 November 2021

Accepted: 8 December 2021

Published: 15 December 202

Publisher's Note: MDPI stays neutral with regard to jurisdictional claims in published maps and institutional affiliations.

Copyright: (c) 2021 by the authors. Licensee MDPI, Basel, Switzerland. This article is an open access article distributed under the terms and conditions of the Creative Commons Attribution (CC BY) license (https:// creativecommons.org/licenses/by/ $4.0 /)$

\begin{abstract}
The extension of the pump-probe approach known from UV/VIS spectroscopy to very short wavelengths together with advanced simulation techniques allows a detailed analysis of excited-state dynamics in organic molecules or biomolecular structures on a nanosecond to femtosecond time level. Optical pump soft X-ray probe spectroscopy is a relatively new approach to detect and characterize optically dark states in organic molecules, exciton dynamics or transient ligand-to-metal charge transfer states. In this paper, we describe two experimental setups for transient soft X-ray absorption spectroscopy based on an LPP emitting picosecond and sub-nanosecond soft X-ray pulses in the photon energy range between 50 and $1500 \mathrm{eV}$. We apply these setups for near-edge X-ray absorption fine structure (NEXAFS) investigations of thin films of a metal-free porphyrin, an aggregate forming carbocyanine and a nickel oxide molecule. NEXAFS investigations have been carried out at the carbon, nitrogen and oxygen K-edge as well as on the Ni L-edge. From time-resolved NEXAFS carbon, K-edge measurements of the metal-free porphyrin first insights into a long-lived trap state are gained. Our findings are discussed and compared with density functional theory calculations.
\end{abstract}

Keywords: NEXAFS; pump-probe; porphyrin; ultrafast X-ray absorption; pseudoisocyanine; TD-DFT

\section{Introduction}

Sir George Porter stated in his Nobel prize lecture [1] that " . . since each molecule has only one ground state, but several excited states, it is clear that this field of investigation is, in principle, a bigger subject than the whole of conventional chemistry ... " This statement was based on his work on flash photolysis [2] using flash lamps as well as first available lasers with pulse durations in the nanosecond range. Now, more than 50 years later, femtochemistry [3] is a well-established technology to prepare and control excited-state species on a very fast time scale using ultrashort femtosecond laser pulses. In this regard, pump-probe spectroscopy using a strong optical pump pulse for the preparation of the excited state and a weaker pulse for probing this state is the main experimental approach [4]. This approach has been successfully applied to detect transient states in organic molecules, such as carbocyanines [5-8], porphyrins [9-14] and polyenes [15-18]. Ultrafast optical transient spectroscopy plays an important role in elucidating charge and energy transfer 
processes in bacterial [18-22] and plant photosynthesis [23-26] as well as ligand-metal interactions $[10,11]$ in catalysis.

The extension of the pump-probe approach to very long or very short wavelengths [27] together with advanced simulation techniques [28-30] allow a detailed analysis of excitedstate dynamics in organic molecules or biomolecular structures on a ns-to-fs time level. Optical pump soft X-ray probe spectroscopy is a relatively new approach to detect and characterize optically dark states in organic molecules [31-34] exciton dynamics $[35,36]$ or transient ligand-to-metal charge transfer states in metalloporphyrins [37].

Optical pump soft X-ray probe spectroscopy can also contribute to understanding structure-function relationships in natural [38] or artificial "molecular machines" [39]. Time-resolved spectroscopic data taken at optical frequencies are not directly related to large molecular structures at an atomic level, whereas time-resolved soft X-ray absorption spectroscopy (tr-XAS) is capable of probing transient structures on an atomic level [39-41]. A detailed knowledge of the molecular structure at an atomic level is indispensable, as was shown, e.g., by X-ray diffraction investigations $[24,38]$ for crystallized parts of the photosynthetic apparatus.

Recent developments on soft X-ray sources, such as high harmonics generation (HHG) [37,42,43] or laser-produced plasma sources (LPP) [34,44,45], open up new opportunities for studying excited-state dynamics in organic molecules on a laboratory scale. In parallel, the above-mentioned improvements in simulation techniques, together with the tremendous increase of computing power, allow understanding the excited-state behavior even of very complex organic molecules in more detail [28].

In this paper, we describe two experimental setups for tr-NEXAFS experiments based on an LPP emitting picosecond and sub-nanosecond soft X-ray pulses in the photon energy range between 50 and $1500 \mathrm{eV}$. As an example, we apply these setups for NEXAFS investigations of thin films of two organic molecules at the carbon and nitrogen K-edge and compare the results with DFT calculations. In addition, we will show that the method is also capable of elucidating the electronic structure of transition metal compounds playing a role, e.g., in metalloporphyrins.

\section{Results and Discussion}

The calculated HOMO and LUMO iso-surfaces of the wave functions of TAP and PIC have been rendered using the software Avogadro with an isosurface value of 0.01 . The result is shown in Figure 1. It can be seen that the wave functions (blue = negative, red $=$ positive) are mainly located at the site of the carbon rings and less at the alkyl substituent, which is common for such organic compounds with conjugated systems.
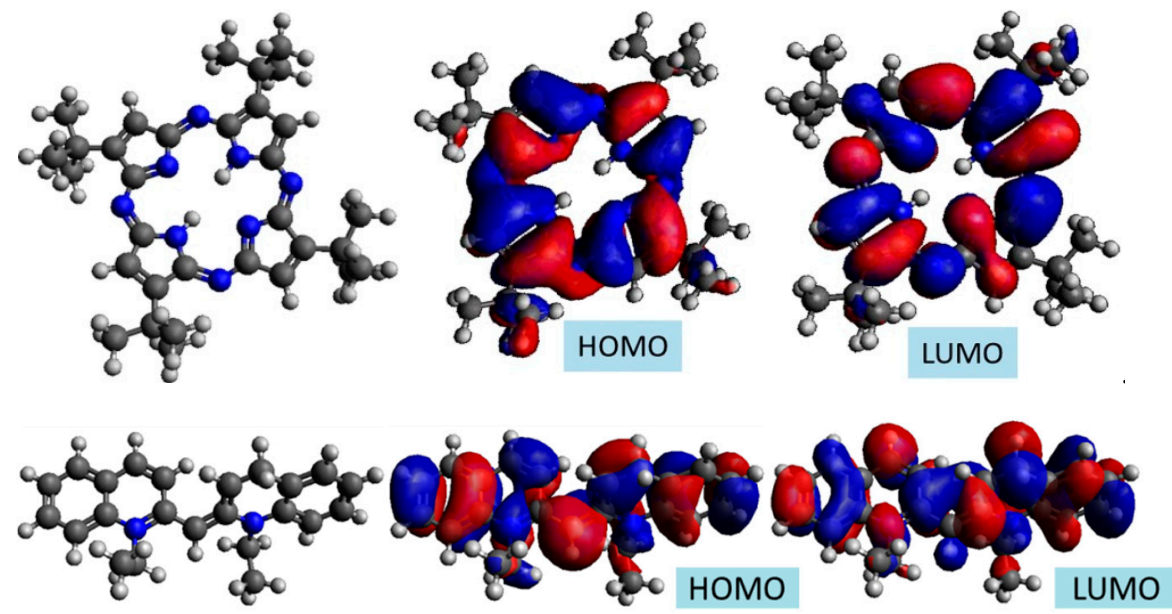

Figure 1. Electronic structure of the HOMO und LUMO of TAP (top) and PIC (bottom). Carbon atoms are depicted in black nitrogen in blue and hydrogen in white. For both molecules, the HOMO and LUMO extends over the whole conjugated system. 
Ground-state NEXAFS measurements of TAP and PIC samples have been performed at the carbon and nitrogen K-edges using the sub-ns LPP source. The measured spectra can be seen in Figure 2. Additionally, the calculated spectra are depicted in grey. The curves of measured and calculated spectra agree well for all edges. Differences in the relative heights of the spectra are partly due to unknown line widths and to the finite number of calculated transitions. The energetic distances of the transitions agree well, which allows an assignment of isolated transitions to the individual atomic groups via the DFT calculation. From the calculation, the individual contributions of the nitrogen atoms to the $\mathrm{C}$ and $\mathrm{N}$ K-edge NEXAFS spectrum can be derived.

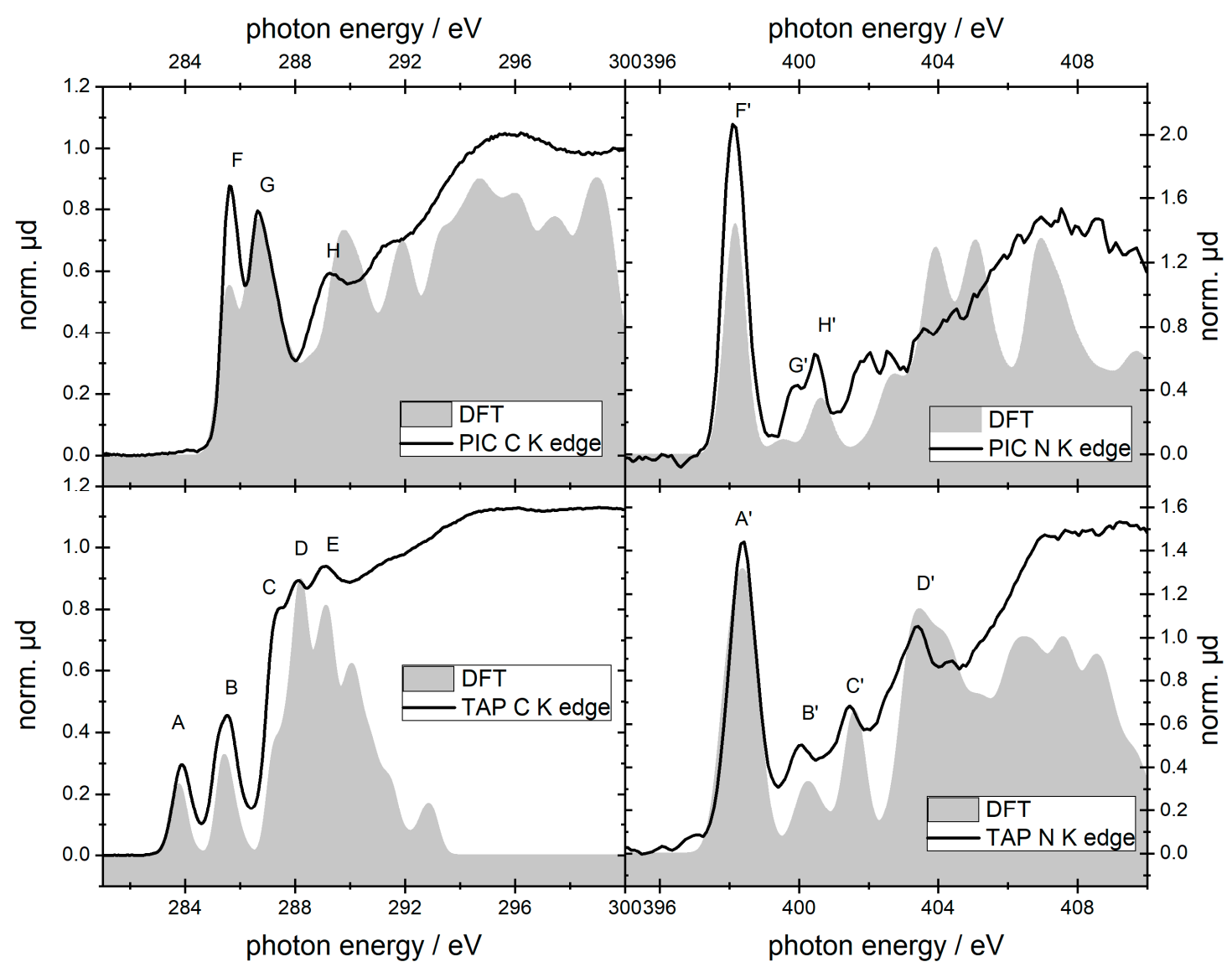

Figure 2. Carbon and nitrogen K-edge NEXAFS spectra of thin films of PIC and TAP in comparison with DFT calculations.

\subsection{TAP}

The assignment of the features in the carbon K-edge spectrum of TAP is summarized in Table 1. It follows the explanations given in [34]. According to our TD-DFT calculations, the two features $\mathrm{A}$ and $\mathrm{C}$ located at 283.9 and $285.4 \mathrm{eV}$ respectively belong to the extended

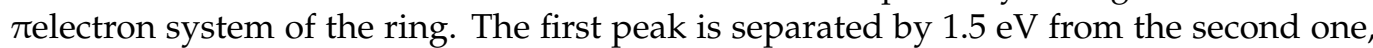
which is very similar to the energetic difference between the SORET- and the Q-band in the UV/Vis spectrum (compare. Figure 11). Features B and E originate from carbon atoms that are only bound to other carbon atoms within the pyrrole ring. Feature D arises solely from the butyl substitution. In the nitrogen K-edge spectrum of TAP, the most prominent feature $\mathrm{A}^{\prime}$ is the strong peak at $398.3 \mathrm{eV}$. This peak can be assigned to the $1 \mathrm{~s} \mathrm{->}$ $\pi^{*}$ LUMO transition on the porphyrin macrocycle. Feature $\mathrm{B}^{\prime}$ and $\mathrm{D}^{\prime}$ at $401.5 \mathrm{eV}$ and 403.4 $\mathrm{eV}$, respectively, are mostly generated by the nitrogen atoms within the pyrrole, which are bound to two carbon atoms and one hydrogen atom. As for the carbon K-edge spectrum, the separation between the peaks $\mathrm{A}^{\prime}$ and $\mathrm{B}^{\prime}$ fits very well with the energetic difference between SORET- and Q-band. Feature $\mathrm{C}^{\prime}$ originates from nitrogen atoms inside of the pyrrole ring that show a double bond with a carbon atom. 
Table 1. Assignment of the measured peak positions for the carbon and nitrogen K-edge NEXAFS spectra of TAP and PIC.

\begin{tabular}{|c|c|c|c|c|c|c|}
\hline & \multirow[b]{2}{*}{ Feature } & \multicolumn{2}{|c|}{ Carbon K-Edge } & \multicolumn{3}{|c|}{ Nitrogen K-Edge } \\
\hline & & Measured (eV) & Assignment & Feature & MEASURED (eV) & Assignment \\
\hline \multirow[t]{5}{*}{ TAP } & A & $283.9 \pm 0.2$ & $C$ bound to $C$ (pyrrole) & $\mathrm{A}^{\prime}$ & $398.4 \pm 0.2$ & N 1s $->\pi^{*}$ LUMO \\
\hline & $\mathrm{B}$ & $285.4 \pm 0.2$ & $\mathrm{C}$ bound to $\mathrm{N}$ (pyrrole) & $\mathrm{B}^{\prime}$ & $400.1 \pm 0.2$ & $\mathrm{~N} 1 \mathrm{~s} \rightarrow \pi^{*} \mathrm{LUMO}+1$ \\
\hline & $\mathrm{C}$ & $287.4 \pm 0.2$ & $\mathrm{C}$ bound to $\mathrm{C}$ (pyrrole) & $\mathrm{C}^{\prime}$ & $401.5 \pm 0.2$ & $\mathrm{~N}$ bound to $\mathrm{H}$ (pyrrole) \\
\hline & $\mathrm{D}$ & $288.2 \pm 0.2$ & $\mathrm{C}$ bound to $\mathrm{C}$ (butyl) & $\mathrm{D}^{\prime}$ & $403.4 \pm 0.2$ & \\
\hline & $\mathrm{E}$ & $289.0 \pm 0.2$ & $\mathrm{C}$ bound to $\mathrm{N}$ (pyrrole) & & & \\
\hline \multirow[t]{3}{*}{ PIC } & $\mathrm{F}$ & $285.7 \pm 0.2$ & $\mathrm{C}$ bound to $\mathrm{C}$ (ring) & $\mathrm{F}^{\prime}$ & $398.1 \pm 0.2$ & N 1s $->\pi^{*}($ LUMO $)$ \\
\hline & G & $286.7 \pm 0.2$ & C bound to $\mathrm{N}$ & $\mathrm{G}^{\prime}$ & $399.8 \pm 0.2$ & N 1s -> LUMO +1 \\
\hline & $\mathrm{H}$ & $289.3 \pm 0.2$ & C (ethyl) & $\mathrm{H}^{\prime}$ & $400.5 \pm 0.2$ & N 1s -> LUMO +3 \\
\hline
\end{tabular}

For the carbon K-edge of TAP, the transient absorption spectra were measured using the sub-nanosecond tr-NEXAFS setup, as already presented in [34]. The sample was excited at the SORET-band with the third harmonic $(343 \mathrm{~nm})$ of the laser with a pulse energy of $1 \mathrm{~mJ} / \mathrm{cm}^{2}$ and a pulse duration of $0.5 \mathrm{~ns}$. The results are shown in Figure 3. The tr-NEXAFS spectrum was taken at several time delays between 0.2 and 43 ns after the excitation. It has been found that these changes remained constant with time delay. Figure 3 shows in blue the averaged differences of all tr-NEXAFS spectra. In order to validate the results and to obtain a reliable value for the uncertainty of the measured absorption difference $\Delta \mathrm{A}$, the difference spectrum with negative time delay (purple curve) is shown. Both curves (blue and purple) have been smoothed into $1 \mathrm{eV}$-bins using a 15-pixel box filter. The estimated uncertainty of the absorption difference is $\pm 5 \times 10^{-4}$. The biggest light-induced change (d2) can be seen between features A and B at feature $B(d 3)$ and between feature B and C (d4). While the transient absorption is reduced for the carbon atoms that are bound to nitrogen, the absorption increased at $\mathrm{d} 1, \mathrm{~d} 2$ and $\mathrm{d} 4$. Because the energy gap between $\mathrm{d} 3$ and $\mathrm{d} 1$ matches the energy of the LUMO-HOMO transition, it can be assumed that the density of unoccupied states in the $\mathrm{d} 3 \mathrm{region}$ is transferred to $\mathrm{d} 1$. The feature $\mathrm{d} 1$ could also possibly arise from an X-ray optical double resonance meaning the $1 \mathrm{~s}$ electron is transferred to a previously occupied state that is partially depleted due to the laser pulse (cp. Figure 8 ). The features $\mathrm{d} 2$ and $\mathrm{d} 4 \mathrm{cannot}$ easily be isolated due to many possible contributions. However, it can be presumed that the butyl groups do not have an effect on the tr-NEXAFS. The observed slow decay channel (lifetime $>43 \mathrm{~ns}$ ) responsible for feature $\mathrm{d} 3$ could be assigned to a long-living trap state. A similar behavior was recently observed by $\mathrm{N}$ K-edge spectroscopy in nonaggregated units in a thin Zn-porphyrin film [46]. To understand the nature of this electronic state, which is unobservable in UV/Vis spectroscopy, in more detail, tr-NEXAFS investigations at the nitrogen K-edge of TAP are planned in the next future. 


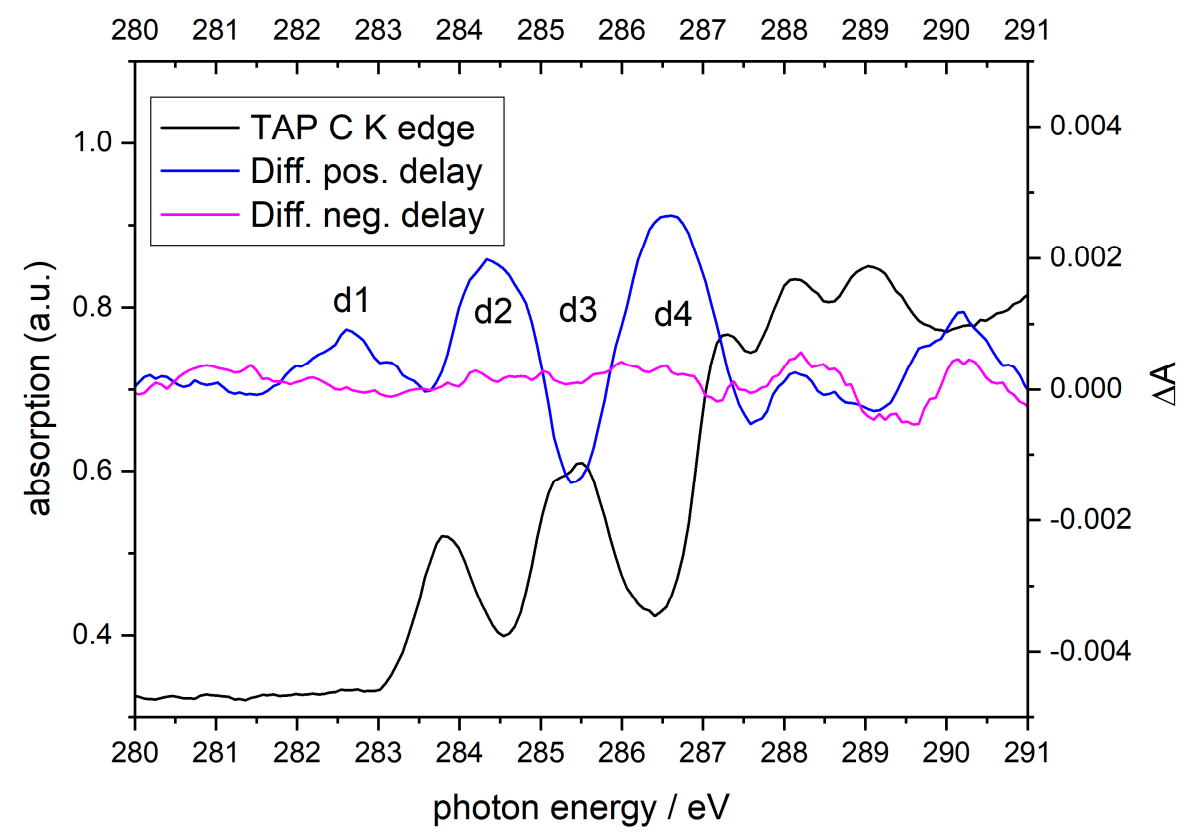

Figure 3. tr-NEXAFS at the carbon K-edge of TAP. The ground state spectrum cf. Figure 2 is shown in black. Die difference spectra with negative and positive time delays between excitation and probing are shown in purple and blue.

\subsection{PIC}

The carbon K-edge spectrum of PIC differs significantly from that of TAP. With many chemical similar carbon atoms, the contributions of the different transitions from the $\mathrm{C}$ K-edge cannot be easily isolated. Still, it can be seen that the lowest energetic transition (feature F) mainly arises from the carbon atoms that are only bonded to other carbon atoms. Feature $\mathrm{G}$ originates from the region around the nitrogen atom, while feature $\mathrm{H}$ emerges from the two ethyl groups. Whereas the peak at $283.9 \mathrm{eV}$ is missing, the NEXAFS spectra show two peaks at $285.7 \mathrm{eV}$ and $286.7 \mathrm{eV}$, separated by only about $1 \mathrm{eV}$. These structures can be assigned to $1 \mathrm{~s}->\pi^{*}$ transitions, whereas both the bandwidth and position of these features are fingerprints of the aggregation state of the dye [36,47]. In our case, the PIC molecules are only weakly coupled, and they are arranged as $\mathrm{H}$-aggregates in the film (cp. Figure 12). To elucidate the influence of the aggregation state on the NEXAFS spectrum of PIC in more detail, alternative thin film preparation techniques are under investigation.

PIC has two nitrogen atoms that have the same chemical environment. Therefore, both nitrogen atoms contribute equally to the NEXAFS. The three features $\mathrm{F}^{\prime}, \mathrm{G}^{\prime}$ and $\mathrm{H}^{\prime}$ can be assigned to transitions of the $\mathrm{N}$ 1s electron into different LUMO states. As for the TAP molecule, the energetic difference between the $\mathrm{F}^{\prime}$ and $\mathrm{G}^{\prime}$ feature is close to the difference of the peak position of the monomeric first $(2.3 \mathrm{eV})$ and second $(3.8 \mathrm{eV})$ excited-state absorption (cp. Figure 12).

\section{3. $\mathrm{NiO}$}

Figure 4a shows the $\mathrm{NiO}$ oxygen K-edge NEXAFS spectrum recorded with the sub-ns LPP together with a spectrum obtained at the synchrotron beamline of PTB (BESSY II-HZB). As can be seen from Figure 4a, the NEXAFS spectrum obtained using the LPP agrees with the related synchrotron data very well, demonstrating the potential of our lab-based NEXAFS. The O K-edge NEXAFS reflects the unoccupied orbital states of the Ni cation that hybridize with the oxygen $2 p$ orbital [48]. There are five main features (A-E) in the NEXAFS spectrum that could be assigned to different electronic states of the molecule (cp. Table 2). 


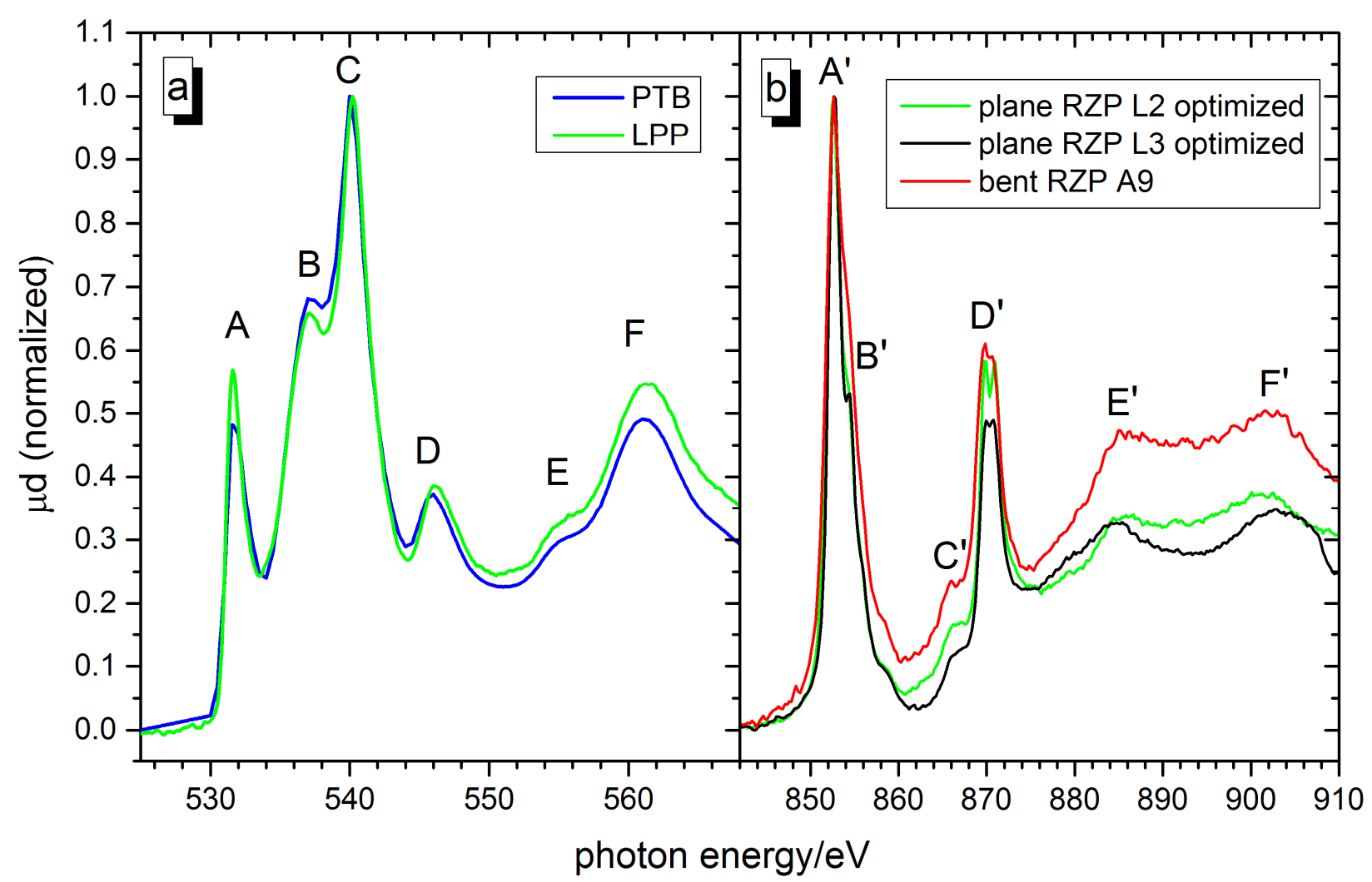

Figure 4. (a) Oxygen K-edge NEXAFS spectra of a NiO thin film measured with the sub-ns laser plasma source (green) and at the PTB/BESSY II synchrotron beamline (blue). (b) Nickel L-edge NEXAFS spectra of a NiO thin film measured with the sub-ns laser plasma source and an RZP on plane substrate optimally aligned for the L2-edge (black) and L3-edge (red), respectively. For comparison, the spectrum (green) recorded with the ps-LPP and the RZP A9 on a bent substrate is also shown.

The lowest-energy feature $\mathrm{A}$ at $531.6 \mathrm{eV}$ can be attributed to a $\mathrm{Ni} 3 \mathrm{~d}^{8}$ state while the features $\mathrm{B}$ and $\mathrm{C}$ at $537.1 \mathrm{eV}$ and $540.0 \mathrm{eV}$ could be assigned to the Ni 4sp state [48]. The features D-F at higher photon energies are mainly due to multiple-scattering effects of the $\mathrm{p}$ photoelectron.

L-edge NEXAFS of Ni as a $3 \mathrm{~d}$ transition metal mainly corresponds to electric dipole transitions from Ni $2 p$ core levels to $3 \mathrm{~d}$ orbitals. Due to the strong correlation between the $3 \mathrm{~d}$ electrons, multiplet structures in the NEXAFS spectrum are predicted by theoretical models [49] using the multi-electron approach. In order to compare these predictions with experimental data in more detail, our measured nickel L-edge NEXAFS spectra were evaluated (Figure $4 \mathrm{~b}$ ). Due to the required high spectral resolution, two different spectrometer settings using the planar RZP in the ns-LPP setup were applied. In order to resolve the L3-edge fine structure (features $\mathrm{A}^{\prime}$ and $\mathrm{B}^{\prime}$ in Figure $4 \mathrm{~b}$ ), the RZP on the plane substrate was optimally aligned for the $853 \mathrm{eV}$ region according to a procedure described in [50]. The features $C^{\prime}$ and $\mathrm{D}^{\prime}$ ("multiplet splitting") could be optimally resolved by alignment of the RZP at $870 \mathrm{eV}$ (L2-edge). For comparison, the spectrum recorded with our proto-type RZP (A9, see above) on a bent substrate is also shown. For this measurement, only $100 \mathrm{im}$ ages each accumulating 2 laser shots of the ps-LPP were processed. The comparable lower statistical amount is close to resolving the line splitting of Ni L2 and feature $\mathrm{A}^{\prime}$. The assignments of the features following theoretical predictions and experimental data $[49,51]$ are summarized in Table 2. 
Table 2. Assignment of the measured peak positions for the oxygen K-edge and nickel L-edge NEXAFS spectra of NiO.

\begin{tabular}{|c|c|c|c|c|c|}
\hline \multicolumn{3}{|c|}{ Oxygen K-Edge } & \multicolumn{3}{|c|}{ Nickel L-Edge } \\
\hline Feature & Measured (eV) & Assignment & Feature & Measured (eV) & Assignment \\
\hline A & $531.6 \pm 0.2$ & $\begin{array}{l}\mathrm{Ni} 3 \mathrm{~d}-\mathrm{O} 2 \mathrm{p} \\
\text { mixing }\end{array}$ & $\mathrm{A}^{\prime}$ & $852.6 \pm 0.2$ & $2 p_{3 / 2}-3 d$ \\
\hline B & $537.1 \pm 0.2$ & $\mathrm{Ni} 4 \mathrm{sp}$ & $\mathrm{B}^{\prime}$ & $854.3 \pm 0.2$ & $2 \mathrm{p}_{3 / 2}-3 \mathrm{~d}$ \\
\hline $\mathrm{C}$ & $540.0 \pm 0.2$ & $\mathrm{Ni} 4 \mathrm{sp}$ & $C^{\prime}$ & $865.9 \pm 0.2$ & $2 p-4 s p[51]$ \\
\hline $\mathrm{D}$ & $546.0 \pm 0.2$ & Multiple scattering & $\mathrm{D}^{\prime}$ & $\begin{array}{l}869.8 \pm 0.2 \\
870.6 \pm 0.2\end{array}$ & $\begin{array}{l}2 \mathrm{p}_{1 / 2}-3 \mathrm{~d}\left(\mathrm{f}_{2 \mathrm{~g}} \mathrm{e}_{\mathrm{g}}\right) \\
\text { Multiplet splitting }\end{array}$ \\
\hline $\mathrm{E}$ & $555.4 \pm 0.2$ & Multiple scattering & $E^{\prime}$ & $885.4 \pm 0.2$ & Multiple scattering \\
\hline $\mathrm{F}$ & $561.2 \pm 0.2$ & Multiple scattering & $\mathrm{F}^{\prime}$ & $902.4 \pm 0.2$ & Multiple scattering \\
\hline
\end{tabular}

\section{Materials and Methods}

\subsection{Experimental}

The two NEXAFS setups are transmission instruments, where polychromatic soft X-rays from a laser-produced plasma source (LPP) are first transmitted through a thin homogeneous sample and successively dispersed with the help of reflection zone plates. The absorption spectra are then collected with a soft X-ray CCD camera as a detector, see, for example, Figure 5. The individual components are described and discussed in the following chapters.

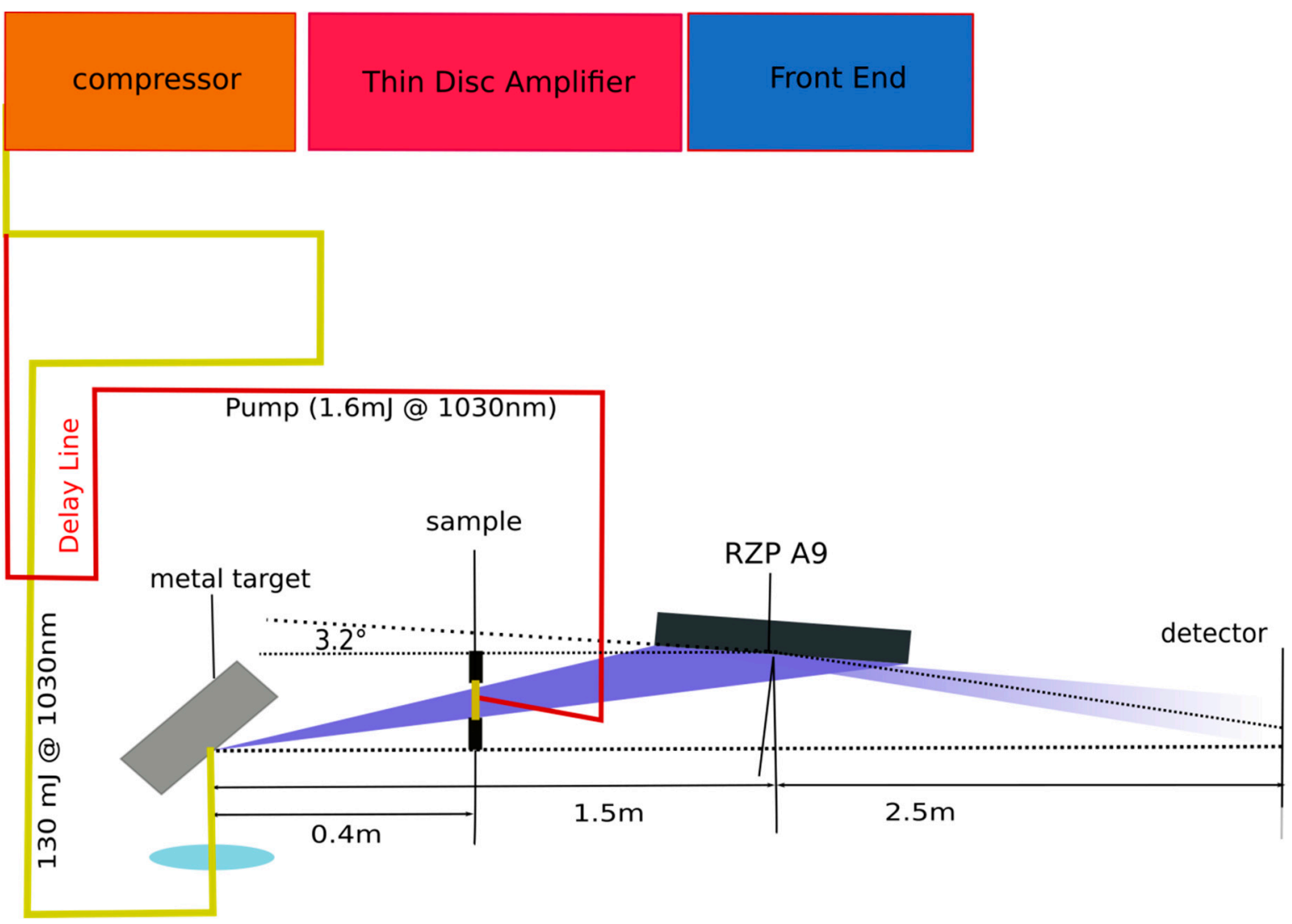

Figure 5. Scheme of the tr-NEXAFS setup using a picosecond driver laser and a reflection zone plate on a bent substrate. 


\subsubsection{Laser Produced Plasma Sources}

In order to generate soft X-ray radiation in the laboratory, we rely on LPP sources. An intense short laser pulse hits a solid target in vacuum and creates a plasma that emits soft X-ray radiation (SXR). In order to meet different requirements concerning achievable time and spectral structure of the SXR radiation, we have developed two LPP sources enabling state-of-the-art NEXAFS spectroscopy in the laboratory.

The first LPP source we want to present is pumped by a chirped pulse amplification (CPA) thin-disk laser system. The driving laser operates at $1030 \mathrm{~nm}$ with a pulse energy of $120 \mathrm{~mJ}$, a 1.2 ps pulse duration and $100 \mathrm{~Hz}$ repetition rate. The plasma is created by focusing the laser pulse on a rotating metal cylinder target. The spot size amounts to $17 \mu \mathrm{m}$ (FWHM) in diameter, delivering an intensity of the target in about $10^{16} \mathrm{~W} / \mathrm{cm}^{2}$. This high intensity on the metal target creates a plasma that emits an X-ray spectrum ranging from $50 \mathrm{eV}$ to $1500 \mathrm{eV}$. Depending on the used target material, the spectrum consists either of characteristic line emission (e.g., $\mathrm{Cu}, \mathrm{Fe}, \mathrm{Sn}$ ) or, for some target elements (e.g., W, Au) with high density of multiplet emission, a quasi-broadband spectrum. The LPP source delivers incoherent soft X-ray (SXR) emission with high photon numbers: $>10^{12}$ photons $/ \mathrm{s}^{*} \mathrm{sr} @$ $0.1 \%$ bandwidth in the range $50-500 \mathrm{eV}$ and $10^{11}$ photons $/ \mathrm{s}^{*} \mathrm{sr} @ 0.1 \%$ bandwidth in the range 500-1500 eV [52]. The pulse duration of the source depends on the pump laser pulse duration as well as on the target material. For a tungsten target and a 1.2 ps pump laser duration, we have estimated an SXR pulse duration at $700 \mathrm{eV}$ of about $10 \mathrm{ps}$ [53].

Both the infrared and the SXR optical path is debris-screened against the ablation of the target material. A $100 \mu \mathrm{m}$ glass plate is used for screening the vacuum window in the pump laser path, and a $900 \mathrm{~nm}$ mylar or parylene foil shields the SXR beamline. Having passed the debris foil, the SXR pulse transmits the sample and is collected by a bent reflection zone plate (RZP A9, see below). The whole setup, including the spectrometer, is depicted in Figure 5.

The second LPP setup with a sub-ns-pulse duration has already been described in detail in previous work [34,45]. In brief, this setup uses an Yb:YAG thin-disk laser system with $200 \mathrm{~mJ}$ maximum single-pulse energy, $100 \mathrm{~Hz}$ repetition rate, 500 ps pulse duration and a solid target for the plasma formation [54]. For the $\mathrm{Cu} X X$ line at $1.1594 \mathrm{~nm}$, a brilliance of $>10^{10} \mathrm{ph} /\left(\mathrm{mm}^{2} \mathrm{mrad}^{2} \mathrm{~s}\right.$ line $)$ is reached. Using the other metal targets values of $>3 \times 10^{11} \mathrm{ph} /\left(\mathrm{mm}^{2} \mathrm{mrad}^{2} \mathrm{~s}\right)$, a line for the water window range, as well as for the EUV, can be achieved [55].

This source utilizes stabilization mechanisms in order to compensate small rotational and translational movements and local variations in the diameter of the target material. The stabilization results in a reduction in source movement from $60 \mu \mathrm{m}$ to $13 \mu \mathrm{m}$ standard deviation with a photon-energy-dependent source diameter between $40 \mu \mathrm{m}$ and $70 \mu \mathrm{m}$.

Both sources cover the whole photon energy region relevant for NEXAFS investigation on organo-metallic compounds, starting from the carbon K-edge up to Mg and Al K-edges, the L-edges of transition metals, as well as M-edges of lanthanides.

For transient experiments, small portions of the laser beam can be used as pump, which are perfectly synchronized to the probe pulse. Both setups offer optical delay lines with variable pump-probe separation (ps setup: 1 ps-1.5 ns, sub-ns setup: $0.5-43 \mathrm{~ns}$ ) and wavelength using non-linear crystals and dye lasers. Due to the complementary temporal pulse structures of the LPPs, transient NEXAFS spectra covering the temporal range for the pump-probe delay from few picoseconds to tens of ns can be recorded.

\subsubsection{Reflection Zone Plate Optics}

The dispersive element in tr-NEXAFS using LPP sources is a critical component. Due to the isotropic nature of the emitted radiation, it should collect the largest emission angle possible. In order to resolve very small features in the tr-NEXAFS spectrum, a resolving power $\mathrm{E} / \Delta \mathrm{E}$ up to 1000 is required. Finally, a high efficiency (throughput) of the optics is crucial for reasonable data acquisition times. Off-axis reflection zone plates (RZPs) are two-dimensional laminar grating structures, where the grating lines follow an 
elliptical shape. They focus and disperse broadband radiation from a point source onto the image plane with high efficiency [56,57]. The design wavelength is concentrated in the focus as the image of the source, while energies smaller and larger than the focus energy are displayed as slightly curved lines in an X-shaped pattern on the detector. The sub-ns NEXAFS setup is equipped with two sets of planar off-axis reflection zone plates (NOB, Nano Optics Berlin GmbH) [45].

RZPs on planar substrates suffer from a relatively narrow energy range with high spectral resolution around the design wavelength. To overcome this limitation, a special "misalignment" technique has been proposed tuning the focused wavelength of a planar RZP over a broader spectral range [50,57]. Another option to obtain a high spectral resolution over a wide photon energy range is to fabricate RZP structures on a spherical substrate [58]. In contrast to an RZP on a planar substrate, the new design allows a high spectral resolution of up to $\Delta \mathrm{E} / \mathrm{E}=1000$ on the detector for a wide spectral range (designenergy $\pm 50 \%$ ) without an energy-dependent spatial and spectral limited focusing. This enables recording a spectrum with retaining one dimension for spatial imaging, similar to commonly used Varied Line-Spaced (VLS) grating. In contrast to a VLS, an RZP on a curved substrate offers a high efficiency up to $25 \%$ in a large spectral range covering photon energies of up to $1300 \mathrm{eV}$ [58].

We tested a prototype (called RZP A9) of this new generation of RZPs that is written on a curved substrate using electron beam lithography. The RZP (NOB Nano Optics Berlin $\mathrm{GmbH}$ ) consists of three different structures, each $10 \mathrm{~mm}$ in height designed for energy of $250 \mathrm{eV}, 500 \mathrm{eV}$, and $780 \mathrm{eV}$, respectively. The radius of curvature of the RZP substrate amounts to $54.879 \mathrm{~m}$, and the angle of incidence is $2.13^{\circ}$ with a reflection angle of $3.52^{\circ}$. The distances between source and RZP and detector and RZP accounted for $1500 \mathrm{~mm}$ and $2500 \mathrm{~mm}$, respectively. On the top and bottom of each structure, the RZP has an additional alignment structure for the design-energy of $966.485 \mathrm{eV}$. The alignment structure represents a miniaturized planar RZP structure. It serves the general alignment of the device as well as for referencing the design energy of the main structure. The RZP A9 was designed to illuminate about $80 \%$ of the area of a 1" CCD chip. As an example, Figure 6 shows two detector images, as seen on the CCD, if one RZP structure has been illuminated by soft $\mathrm{X}$-rays from our ps-LPP source.

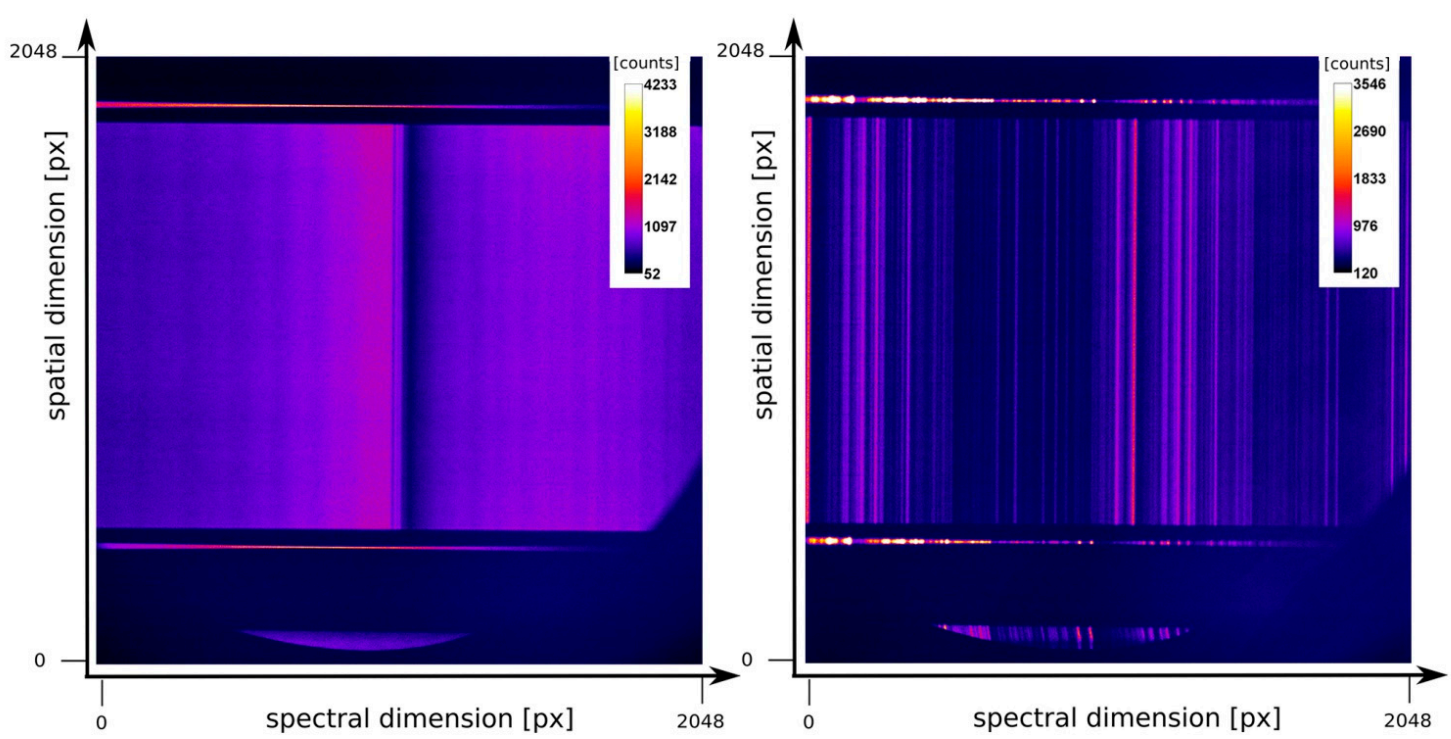

Figure 6. Detector image of a tungsten spectrum (Left) taken with the so-called S2 structure (design energy $450 \mathrm{eV}$ ) of the RZP A9. In the reference structure on the top and bottom, the oxygen K-edge absorption from the mylar foil is visible. (Right): Detector image of an iron spectrum taken with the so-called S3 structure (design energy $780 \mathrm{eV}$ ). Design energy of the reference structure: $966.45 \mathrm{eV}$. The integration time was $945 \mathrm{~ms}$ at a laser repetition rate of $100 \mathrm{~Hz}$. Detector: Back-illuminated soft X-ray CCD camera (Greateyes $\mathrm{GmbH})$. 


\subsubsection{General Considerations for Optical Pump X-ray Probe Experiments on} Organic Molecules

In optical pump X-ray probe experiments, molecules are excited with a light pulse. Afterwards, the X-ray spectrum of the excited molecule is detected. By varying the time delay between the two short pulses, the temporal evolution of the system can be investigated. The achievable time resolution is given by the longer pulse duration, which is, in most cases, the X-ray pulse durations. Figure 7 illustrates the pump-probe scheme for a typical organic molecule. The optical pump pulse tuned to a transition between the ground singlet state $S_{0}$ and an excited state of the molecule $\left(S_{1}, S_{2}, \ldots\right)$ creates a vacancy in the highest occupied molecular orbital (HOMO), which is detected by an X-ray pulse tuned to the Kor L-absorption edge of the atom of interest.

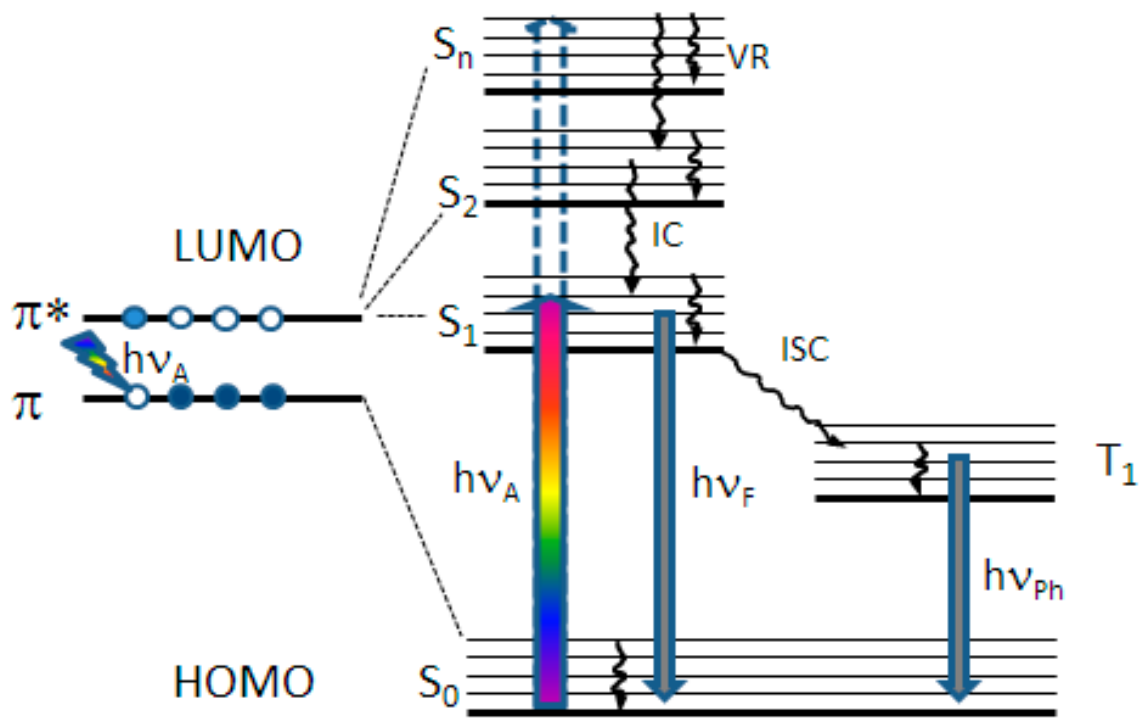

Figure 7. Term scheme illustrating the principle of an optical pump (multi-color arrow, $\mathrm{h} v_{\mathrm{A}}$ ) and $X$-ray probe experiment for a typical organic molecule. The optical pump pulse tuned to a transition between $S_{0}$ and an excited state of the molecule $\left(S_{1}, S_{2}, \ldots\right)$ creates a vacancy in the highest occupied molecular orbital (HOMO), which is detected by an X-ray pulse tuned to the K- or L-absorption edge of the atom of interest. LUMO denotes the lowest unoccupied molecular orbital related to an excited singlet state of the molecule. $\mathrm{h} v_{\mathrm{F}}$ : fluorescence, $\mathrm{h} v_{\mathrm{Ph}}$ : phosphorescence, IC: internal conversion, VR: vibrational relaxation. ISC: intersystem crossing.

For successful tr-NEXAFS, it is necessary to excite a sufficient number of molecules depending on the achievable signal-to-noise ratio (SNR) of the setup and the strength of the transient signal. Compared to measurements in liquids, where rapid sample replenishment is possible, the excitation percentage of molecular thin films is often limited to single digits due to radiation-induced damage and sample evaporation. Typical damage thresholds for thin films of organic molecules on $\mathrm{Si}_{3} \mathrm{~N}_{4}$ or SiC membranes are in the range of $1-5 \mathrm{~mJ} / \mathrm{cm}^{2}$. If evaporation due to sample heating is the dominating factor, the maximum power density is almost independent of the pulse length.

Since the absorption coefficient of the optical pump is usually much higher compared to the X-ray probe pulse the maximum sample thickness is determined by the optical pulse, which leads to optically thin samples for the $X$-ray pulse. The consequence of the low excitation ratio and optically thin samples for $\mathrm{X}$-rays is a small absorption difference in the range of $10^{-2}$ to $10^{-4}$. The SNR needed to detect this transient change can only be achieved by taking multiple measurements. This requires a stable setup and will be discussed in the detectors and data acquisition section.

To determine the damage threshold and excitation ratio before the tr-XAS experiment, non-linear absorption (NLA) measurements can be conducted. In an NLA setup, the absorption of a laser through the sample is detected for increasing laser intensities. When part 
of the sample is excited during the laser pulse, the transmission becomes non-linear due to ground state bleaching. This allows the estimation of the excited-state fraction and modeling of the energy level scheme using a rate equation system for the population densities and a photon transport equation for the radiation transport through the sample [31].

\subsection{Materials}

In order to evaluate the potential of our lab-based tr-NEXAFS setups, we choose three sample systems, see Figure 8: (i) a metal-free porphyrin, (ii) an aggregate forming carbocyanine and (iii) a nickel oxide sample. The metal-free tetra(tert-butyl)-porphyrazine (TAP) is a typical molecule belonging to the class of tetrapyrroles, which exhibits great application potential in optoelectronics and photovoltaics, as well as pigments in natural or artificial photosynthesis. Pseudoisocyanine (1,1'-Diethyl-2,2'-cyanine iodide, PIC) is a J-aggregate forming carbocyanine. J-aggregates of PIC could be regarded as supramolecular polymers that show exceptional photophysical properties, such as giant dipole transition moments and strong exciton-exciton annihilation. $\mathrm{NiO}$ as a typical large bandgap semiconductor is applied in photovoltaic solar cells and as an anode material in lithium battery technology. Ni-porphyrin molecules are promising candidates for organic solar cells. The knowledge of its electronic properties is crucial for optimizing the efficiency of these devices.<smiles></smiles>

TAP

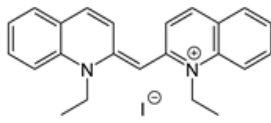

PIC
$\mathrm{O}==\mathrm{Ni}$

$\mathrm{NiO}$

Figure 8. Structure of the three samples under investigation: TAP = tetra(tert-butyl)-porphyrazine), $\mathrm{PIC}=1,1^{\prime}$-diethyl-2,2' -cyanine iodide and $\mathrm{NiO}=$ nickel oxide.

Both tr-NEXAFS setups rely on the detection of transmitted radiation through a sample, where the thickness of the sample determines the contrast at the absorption edge and the number of detected photons. Therefore, large, homogeneous thin samples are required. Typically, organic molecule samples are deposited on $150 \mathrm{~nm}$ thin $\mathrm{Si}_{3} \mathrm{~N}_{4}$ membranes with a window size of $1 \mathrm{~mm} \times 2 \mathrm{~mm}$ or $2 \mathrm{~mm} \times 2 \mathrm{~mm}$ via spin coating or evaporation using an effusion cell. The choice of preparation is dependent on the chemical properties of the molecule, such as solvability or evaporation temperature (see Supplemental Information for details).

After preparation, the organic samples are also pre-characterized to NLA measurements using UV/Vis spectroscopy, an EUV spectrometer for thickness determination and an atomic force microscope (AFM).

Details concerning instrumentation and measurement parameters can be found in the Supplementary Material (Table S1).

\section{3. $\mathrm{NiO}$}

The $\mathrm{NiO}$ samples were prepared on $200 \mathrm{~nm}$ thick $\mathrm{Si}_{3} \mathrm{~N}_{4}$ windows $(3 \times 3 \mathrm{~mm})$ by depositing Ni using a reactive electron beam evaporation in an oxygen environment at room temperature. The thickness we monitored with a quartz crystal and the stoichiometry with EDX measurements delivered an O:Ni ratio of about 51:48 (see Figures S1 and S2). Figure 9 shows the UV/Vis spectrum of a $300 \mathrm{~nm}$ thick $\mathrm{NiO}$ sample with the bandgap energy of $\mathrm{NiO}$ at $3.6 \mathrm{eV}$ [59]. This value is very close to the photon energy of the third harmonic of the pump laser. The optical density $(\mathrm{OD}=-\log (\mathrm{T}))$ at $3.6 \mathrm{eV}$ accounts for 0.54 . In comparison, the related value in the Ni L-edge region (850-870 eV) amounts to 1.1. 


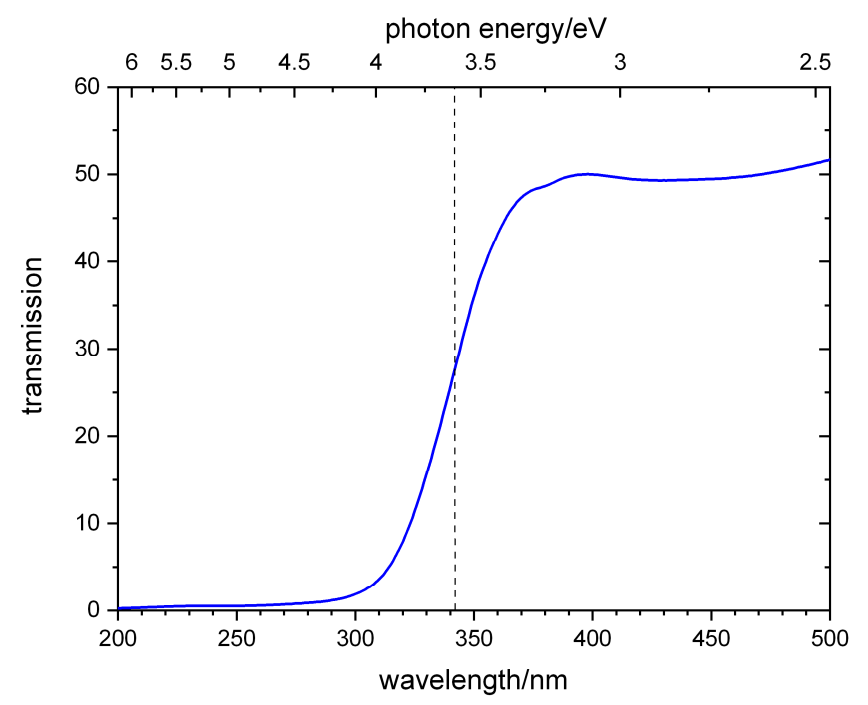

Figure 9. UV/Vis spectrum of the $\mathrm{NiO}$ sample (thickness $300 \mathrm{~nm}$ ) on $\mathrm{Si}_{3} \mathrm{~N}_{4}$ corrected for substrate transmission.

\subsection{TAP}

TAP thin films were prepared by evaporation on $1 \times 1 \mathrm{~mm}^{2} \mathrm{Si}_{3} \mathrm{~N}_{4}$ membranes. The UV/Vis spectrum of such a $120 \mathrm{~nm}$ thick film in comparison to TAP solved in ethanol ( $\mathrm{c}=3.6 \times 10^{-4} \mathrm{~mol} / \mathrm{L}, 1 \mathrm{~mm}$ quartz cuvette) is shown in Figure 11. In porphyrins and its derivatives, the $S_{1}$ state splits into two states due to molecular symmetry, which are named $\mathrm{Q}_{\mathrm{x}}$ and $\mathrm{Q}_{\mathrm{y}}$. Transitions to the $\mathrm{S}_{2}$ state led to the formation of the Soret band or $\mathrm{B}$ band [60].

Figure 10 (inset) shows the thickness distribution using the EUV spectrometer of a $2 \mathrm{~mm} \times 2 \mathrm{~mm}$ TAP sample (thickness: $250 \mathrm{~nm}$ ) after a pump-probe NEXAFS measurement. The pixel values of the CCD images were converted into TAP film thickness using the formalisms explained in [61]. Inhomogeneities in the order of $20 \mathrm{~nm}$ to $30 \mathrm{~nm}$ can be seen with an average thickness of $250 \mathrm{~nm}$. The relative error of the EUV transmission measurement is estimated to be $20 \%$, and the lateral resolution was $25 \mu \mathrm{m}$. The dark dots are small debris particles from the LPP as the sample was not protected by a debris foil in this measurement.

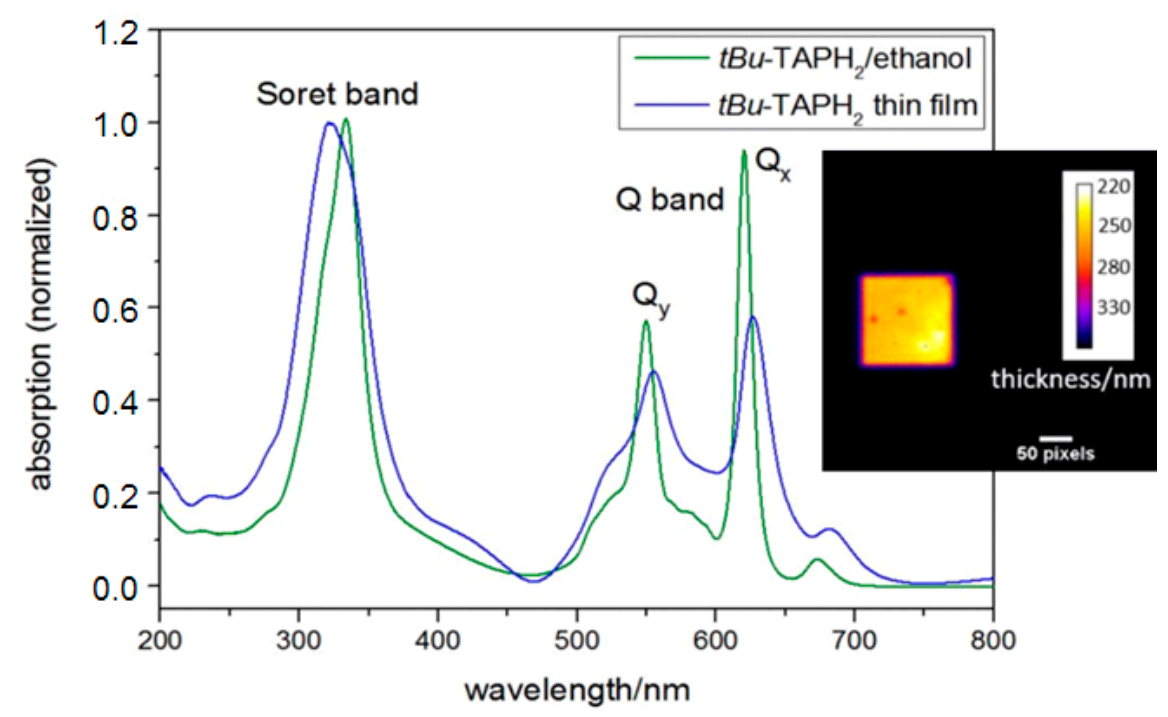

Figure 10. UV/Vis spectrum of TAP in solution and prepared as a thin film (thickness of $120 \mathrm{~nm}$ ). Inset: EUV transmission image of a thin film TAP sample (thickness about $250 \mathrm{mn}$ ). 


\subsection{PIC}

PIC thin films were also prepared by evaporation. The UV/Vis spectrum of a $250 \mathrm{~nm}$ thick PIC sample is depicted in Figure 11. The solution at concentrations below $10^{-4} \mathrm{~mol} / \mathrm{L}$ in a $1 \mathrm{~mm}$ thick quartz cuvette shows absorption bands located at $527 \mathrm{~nm}$, whereas an increase in the concentration leads to the appearance of the characteristic J-band at $573 \mathrm{~nm}$. Our preparation technique results in the formation of a mixture of monomers and $\mathrm{H}$ aggregates in the film with a hypsochromic shift of the H-aggregate absorption band in comparison with the monomer. This behavior is in contrast to other works using a spin coating preparation technique, which results in the formation of J-aggregates [62]. Because in our case the preparation starts with a dye powder rather than an aqueous solution as in [62], the thin film contains mainly H-aggregates and monomers. Simulations of the aggregation process during thin film formation suggest a strong dependence of PIC aggregation on the initial conditions of the preparation process, indicating that, in most cases, a mixture of different aggregates and monomers exits [63].

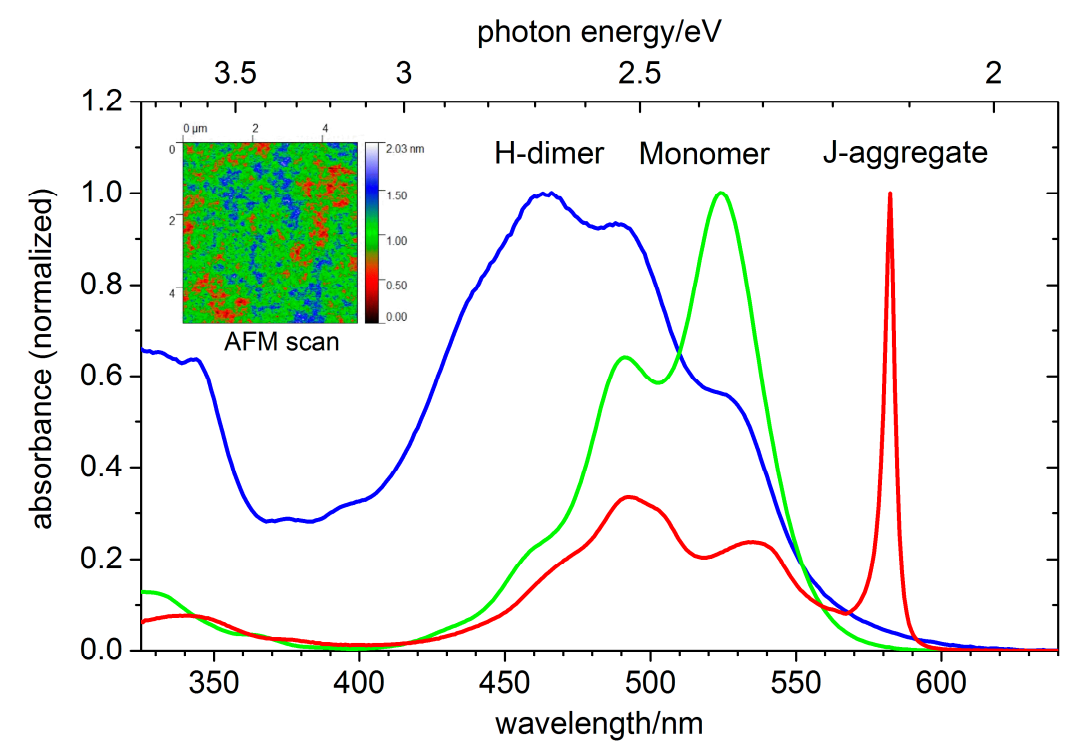

Figure 11. UV/Vis absorption of PIC. The thin film spectrum (blue) shows a blue shift in comparison with the monomer (green curve) spectrum in solution, indicating an H-aggregation of the film. At concentrations $>10^{-2} \mathrm{~mol} / \mathrm{L}$, the characteristic J-band appears (red curve) in aqueous solution. inset: AFM analysis of the homogeneity of the prepared thin film (thickness $270 \mathrm{~nm}$ ).

For the $270 \mathrm{~nm}$ thick PIC sample, an AFM image of a $5 \mu \mathrm{m} \times 5 \mu \mathrm{m}$ and a line scan on the edge were performed (cp. Inset in Figure 11). The deviation from the $\mathrm{z}=0$ position of the AFM tip is shown in the color scale. On the nanometer scale, the film thickness only varies about $1 \mathrm{~nm}$ to $2 \mathrm{~nm}$. The line scan at the edge of the sample shows a film thickness of $300 \mathrm{~nm} \pm 10 \mathrm{~nm}$, which agrees with EUV transmission measurements.

\subsection{DFT Simulations}

Calculations based on time-dependent density functional theory (TD-DFT) with the aid of the freeware ORCA [64] were performed to better understand the carbon and nitrogen K-edge absorption spectra. Information from these calculations includes the shape of the HOMO and LUMO, the shape of the NEXAFS spectrum and the assignment of the NEXAFS structures to the involved transitions of the corresponding atoms. For the TD-DFT calculation, the B3LYP functional, together with the def2-TZVP, basis set was used. The RIJCOSX approximation was employed using the auxiliary basis set def $2 / \mathrm{J}$. This level of theory was also used to optimize the geometry of the PIC molecule. The geometry of the TAP molecule was optimized by using the universal force field (UFF) method. 
TD-DFT calculations deliver oscillator strengths of the first 100 electronic transitions at the respective energy as a delta function for each atom. The delta functions were subsequently convolved with Gaussian functions with a full width at half maximum of $0.5 \mathrm{eV}$ to better reflect the actual shape of the experimental NEXAFS spectrum. The whole spectrum is then uniformly shifted by several $\mathrm{eV}$.

\subsection{Detectors and Data Acquisition}

The standard detectors used are soft X-ray CCD cameras (Greateyes GE 2048 BI) with read-out times of a few hundreds of ms-seconds depending on the number of pixels binned. Alternatively, CMOS detectors offer the possibility for a faster acquisition [44].

For the sub-ns setup, the reference and sample spectra are focused with pairs of RZP optics onto the large $(27.6 \mathrm{~mm} \times 27.6 \mathrm{~mm})$ sensor area, rendering single-shot NEXAFS spectroscopy feasible. Additionally, a pinhole positioned in the direct path between the source and the detector enables the imaging of the source positions and intensity. NEXAFS measurements using this setup are described in detail in [45]. For the measurements at the carbon K-edge and N K-edge of PIC and TAP samples between 200-20,000 images have been collected. For the $\mathrm{NiO} O \mathrm{~K}$-edge and $\mathrm{NiO} \mathrm{Ni}$ L-edge measurements, around 4000 images were processed. For tr-NEXAFS measurements on TAP, the experimental details are summarized in [34].

The ps- setup (cf. Figure 5) with the prototype RZP A9 used full-frame measurements of the 1 " CCD detector for either the reference or sample transmitted signal. Hence, the pssetup with the prototype RZP does not yet allow a coincident reference and measurement signal (cf. Figure 6) nor a faster readout by binning. Concerning the source pointing correction, this setup uses a post-evaluation correction applied on close-to-single laser shot measurement series. Measurements with this setup on the Ni L-edge processed measurement series of about 100 images.

Further details of the NEXAFS measurements and its evaluation methods are described in [45] and in Table S1 in the Supplemental Information.

\section{Conclusions and Outlook}

We have developed an experimental approach for elucidating the structure of transient electronic states using ultrafast laboratory-based soft X-ray sources. For this purpose, highly brilliant soft $X$-ray sources were developed, as well as measurement schemes adapted. In order to obtain the required high spectral resolution, advanced X-ray optics with reflection zone plates as dispersive elements were applied. Here, the development of structures on curved substrates enhances the spectral range of high resolving power by a factor of more than 30, rendering efficient analysis of multiple edges feasible. Additionally, EXAFS measurements become easily accessible.

We presented the first measurements with a prototype RZP on a bent substrate in the photon energy range at $850 \mathrm{eV}$. We could show that this new optical element provides a high spectral resolution for a wide spectral range close to the resolving power of optimized methods for planar RZPs. With a higher number of recorded images, the statistics and by this the resolving power could be improved, favorably with using an sCMOS detector for a significantly shorter read-out time [44]. The current development of this experimental setup focuses on the coincident measurement using two RZPs on curved substrates as on the optimization of alignment routines and post-processing.

With these new laboratory instruments, we pave the way for state-of-the-art trNEXAFS spectroscopy independent of large-scale facilities. Thereby, a variety of application fields is opening up, which are by no means restricted to organo-molecular films. The adaption of our approach to other ultrafast lab-based sources, such as harmonics generation [65], is under the way and could extend the time resolution for soft X-ray absorption investigations to the attosecond range [43].

Our TD-DFT calculations carried out for the TAP and PIC films explain the measured NEXAFS spectra well and assign the observed spectral features to the electronic structure 
of the molecule in its ground state. The simulation of the NEXAFS spectrum of an optically excited state (as for tr-NEXAFS) requires a higher effort (for porphyrin molecules cp. [29]), and it was not in the scope of this publication. However, such simulations are planned for the future.

Besides the possibility to detect and characterize transient electronic states, our labbased tr-NEXAFS approach allows the investigation of thermally or non-thermally induced phase transitions as well as relatively slow in situ reactions or slow dynamic processes in catalysis [66]. The application of our setup for quick X-ray absorption fine structure measurements on $\mathrm{Ni} / \mathrm{TiO}_{2}$ nanostructures is described in [44].

For successful tr-NEXAFS experiments, pre-characterization of samples is a prerequisite. Through the careful matching of optical pump pulse parameters using UV/Vis spectroscopy and NLA measurements, radiation damage of the sample can be minimized or prevented and transient contrasts enhanced. The design of the spectrometers additionally minimizes radiation damage, as, on the one hand, both the pump and the probe pulse have large footprints on the sample. On the other hand, the systems operate completely background-free, i.e., no residual (probe) light reaches the samples in between pulses. Since the complete spectrum is measured for each laser shot, energy scanning is not necessary, which reduces the radiation dose significantly. Nevertheless, the optical pumping does lead to heating of the samples, thereby possibly introducing temperature effects that complicate the analysis of the transient signals. For this purpose, a sample holder for static temperature measurements is designed for our setups. With this holder, first UV/Vis experiments were conducted, which allow choosing an optimal wavelength for pumping by selecting the wavelength with minimal change in the UV/Vis spectrum. In the future, for each new sample system, a pre-characterization concerning temperature effects will be implemented in the experimental methodology. Since heat loss by thermal radiation is high compared to heat transfer by conduction in nanometer-thin films, the sample holder will use hot gas to heat the sample evenly in the future. A very promising approach to prevent sample damage due to heating effects is the usage of a liquid flat jet carrying the molecule of interest in the solution [67]. However, this approach requires a relatively high volume of sample molecules, not applicable, i.e., for specially prepared parts of photosynthetic apparatus. To overcome this limitation, a liquid cell for transmission measurements on molecules in a solution based on an existing cell for fluorescence experiments [68] is under development.

Supplementary Materials: Supplementary materials can be found at https://www.mdpi.com/ article/10.3390/ijms222413463/s1.

Author Contributions: Conceptualization: J.B., I.M., A.J. and H.S.; Methodology: J.T., D.S., R.G., L.T.G., A.E. and T.K. All authors have read and agreed to the published version of the manuscript.

Funding: Part of this work was funded by Deutsche Forschungsgemeinschaft (\# 313838950). HS and JB are grateful for support from ProFit (MOSFER \# 10168892). TK and AE are grateful for support from ProFit (MOSFER \# 10168775), AE is grateful for support from ProFit (MOSFER \# 10168769).This project has received funding from the European Union's Horizon 2020 research and innovation program under grant agreement no. 871124 Laserlab-Europe.

Institutional Review Board Statement: Not applicable to our research topic.

Informed Consent Statement: Not applicable to our research topic.

Data Availability Statement: The authors confirm that the data supporting the findings of this study are available within the article and its supplementary materials.

Acknowledgments: The authors would like to thank B. Beckhoff (PTB) and R. Unterumsberger (PTB) for providing the NiO NEXAFS measurements at the SX700 beamline at BESSYII Berlin.

Conflicts of Interest: The authors declare no conflict of interest. 


\section{References}

1. Porter, G. Flash Photolysis and Some of Its Applications, Nobel Lecture. 11 December 1967. Available online: https://www. nobelprize.org/prizes/chemistry/1967/porter/lecture/ (accessed on 12 October 2021).

2. Porter, G.; Topp, M.R. Nanosecond flash photolysis and absorption spectra of excited singlet states. Nature 1968, 220, 1228-1229. [CrossRef]

3. Zewail, A.H. Femtochemistry: Atomic-scale dynamics of the chemical bond. J. Phys. Chem. A 2000, 104, 5660-5694. [CrossRef]

4. Maiuri, M.; Garavelli, M.; Cerullo, G. Ultrafast Spectroscopy: State of the Art and Open Challenges. J. Am. Chem. Soc. 2020, 142, 3-15. [CrossRef]

5. Meyer, Y.H.; Pittman, M.; Plaza, P. Transient absorption of symmetrical carbocyanines. J. Photochem. Photobiol. A Chem. 1998, 114, 1-21. [CrossRef]

6. Ma, F.; Yartsev, A. Ultrafast photoisomerization of pinacyanol: Watching an excited state reaction transiting from barrier to barrierless forms. RSC Adv. 2016, 6, 45210-45218. [CrossRef]

7. Bruggemann, B.; May, V. Exciton exciton annihilation dynamics in chromophore complexes. II. Intensity dependent transient absorption of the LH2 antenna system. J. Chem. Phys. 2004, 120, 2325-2336. [CrossRef]

8. Ma, F. Dynamics and Coherent Control of Exciton-Exciton Annihilation in Aqueous J-Aggregate. J. Phys. Chem. B 2018, 122, 10746-10753. [CrossRef]

9. Stiel, H.; Volkmer, A.; Ruckmann, I.; Zeug, A.; Ehrenberg, B.; Röder, B. Non-linear and transient absorption spectroscopy of magnesium(II)-tetrabenzoporphyrin in solution. Opt. Commun. 1998, 155, 135-143. [CrossRef]

10. Gobeze, H.B.; Das, S.K.; D'Souza, F. Femtosecond Transient Absorption Study of Supramolecularly Assembled Metal TetrapyrroleTiO2 Thin Films. J. Phys. Chem. C 2014, 118, 16660-16671. [CrossRef]

11. Ha-Thi, M.H.; Pham, V.T.; Pino, T.; Maslova, V.; Quaranta, A.; Lefumeux, C.; Leibl, W.; Aukauloo, A. Photoinduced electron transfer in a molecular dyad by nanosecond pump-pump-probe spectroscopy. Photochem. Photobiol. Sci. 2018, 17, 903-909. [CrossRef]

12. Kim, D.; Kirmaier, C.; Holten, D. Nickel porphyrin photophysics and photochemistry. A picosecond investigation of ligand binding and release in the excited state. Chem. Phys. 1983, 75, 305-322. [CrossRef]

13. Zamyatin, A.V.; Gusev, A.V.; Rodgers, M.A.J. Two-pump-one-probe femtosecond studies of Ni(II) porphyrins excited states. J. Am. Chem. Soc. 2004, 126, 15934-15935. [CrossRef] [PubMed]

14. Shelby, M.L.; Lestrange, P.J.; Jackson, N.E.; Haldrup, K.; Mara, M.W.; Stickrath, A.B.; Zhu, D.; Lemke, H.T.; Chollet, M.; Hoffman, B.M.; et al. Ultrafast Excited State Relaxation of a Metalloporphyrin Revealed by Femtosecond X-ray Absorption Spectroscopy. J. Am. Chem. Soc. 2016, 138, 8752-8764. [CrossRef]

15. Larsen, D.S.; Papagiannakis, E.; van Stokkum, I.H.M.; Vengris, M.; Kennis, J.T.M.; van Grondelle, R. Excited state dynamics of b-carotene explored with dispersed multi-pulse transient absorption. Chem. Phys. Lett. 2003, 381, 733-742. [CrossRef]

16. Vdovic, S.; Wang, Y.Y.; Li, B.X.; Qiu, M.; Wang, X.F.; Guo, Q.J.; Xia, A.D. Excited state dynamics of beta-carotene studied by means of transient absorption spectroscopy and multivariate curve resolution alternating least-squares analysis. Phys. Chem. Chem. Phys. 2013, 15, 20026-20036. [CrossRef]

17. Antognazza, M.R.; Luer, L.; Polli, D.; Christensen, R.L.; Schrock, R.R.; Lanzani, G.; Cerullo, G. Ultrafast excited state relaxation in long-chain polyenes. Chem. Phys. 2010, 373, 115-121. [CrossRef]

18. Polivka, T.; Sundström, V. Ultrafast dynamics of carotenoid excited states-from solution to natural and artificial systems. Chem. Rev. 2004, 104, 2021-2071. [CrossRef]

19. Kosumi, D.; Maruta, S.; Horibe, T.; Fujii, R.; Sugisaki, M.; Cogdell, R.J.; Hashimoto, H. Ultrafast Energy-Transfer Pathway in a Purple-Bacterial Photosynthetic Core Antenna, as Revealed by Femtosecond Time-Resolved Spectroscopy. Angew. Chem. Int. Ed. 2011, 50, 1097-1100. [CrossRef]

20. Zinth, W.; Wachtveitl, J. The first picoseconds in bacterial photosynthesis-Ultrafast electron transfer for the efficient conversion of light energy. Chemphyschem 2005, 6, 871-880. [CrossRef]

21. Finkele, U.; Lauterwasser, C.; Struck, A.; Scheer, H.; Zinth, W. Primary electron transfer kinetics in bacterial reaction centers with modified bacteriochlorophylls at the monomeric sites BA,B. Proc. Natl. Acad. Sci. USA 1992, 89, 9514-9518. [CrossRef] [PubMed]

22. Yukihira, N.; Sugai, Y.; Fujiwara, M.; Kosumi, D.; Iha, M.; Sakaguchi, K.; Katsumura, S.; Gardiner, A.T.; Cogdell, R.J.; Hashimoto, H. Strategies to enhance the excitation energy-transfer efficiency in a light-harvesting system using the intramolecular charge transfer character of carotenoids. Faraday Discuss. 2017, 198, 59-71. [CrossRef]

23. Klug, D.R.; Rech, T.; Joseph, D.M.; Barber, J.; Durrant, J.R.; Porter, G. Primary processes in isolated photosystem-II reaction centers probed by magic-angle transient absorption spectroscopy. Chem. Phys. 1995, 194, 433-442. [CrossRef]

24. Croce, R.; van Amerongen, H. Light harvesting in oxygenic photosynthesis: Structural biology meets spectroscopy. Science 2020, 369, eaay2058. [CrossRef] [PubMed]

25. Lambrev, P.H.; Akhtar, P.; Tan, H.S. Insights into the mechanisms and dynamics of energy transfer in plant light-harvesting complexes from two-dimensional electronic spectroscopy. BBA-Bioenergetics 2020, 1861, 148050. [CrossRef] [PubMed]

26. Holleboom, C.P.; Walla, P.J. The back and forth of energy transfer between carotenoids and chlorophylls and its role in the regulation of light harvesting. Photosynth. Res 2014, 119, 215-221. [CrossRef] 
27. Ross, M.; Andersen, A.; Fox, Z.W.; Zhang, Y.; Hong, K.; Lee, J.-H.; Cordones, A.; March, A.M.; Doumy, G.; Southworth, S.H.; et al. Comprehensive Experimental and Computational Spectroscopic Study of Hexacyanoferrate Complexes in Water: From Infrared to X-ray Wavelengths. J. Phys. Chem. B 2018, 122, 5075-5086. [CrossRef] [PubMed]

28. Segatta, F.; Nenov, A.; Orlandi, S.; Arcioni, A.; Mukamel, S.; Garavelli, M. Exploring the capabilities of optical pump X-ray probe NEXAFS spectroscopy to track photo-induced dynamics mediated by conical intersections. Faraday Discuss. 2020, 221, 245-264. [CrossRef]

29. Pandey, R.K.; Mukamel, S. Simulation of X-ray absorption near edge spectra of organometallic compounds in the ground and optically excited states. J. Phys. Chem. A 2007, 111, 805-816. [CrossRef]

30. Kowalewski, M.; Fingerhut, B.P.; Dorfman, K.E.; Bennett, K.; Mukamel, S. Simulating Coherent Multidimensional Spectroscopy of Nonadiabatic Molecular Processes: From the Infrared to the X-ray Regime. Chem. Rev. 2017, 117, 12165-12226. [CrossRef]

31. Stiel, H.; Leupold, D.; Beck, M.; Will, I.; Lokstein, H.; Sandner, W. Towards time resolved, coupled structure-function information on carotenoid excited state processes: X-ray and optical short pulse double resonance spectroscopy. J. Biomed. Biophys. Methods 2001, 48, 239-246. [CrossRef]

32. Wolf, T.J.A.; Myhre, R.H.; Cryan, J.P.; Coriani, S.; Squibb, R.J.; Battistoni, A.; Berrah, N.; Bostedt, C.; Bucksbaum, P.; Coslovich, G.; et al. Probing ultrafast $\pi \pi^{*} / \mathrm{n} \pi^{*}$ internal conversion in organic chromophores via K-edge resonant absorption. Nat. Commun. 2017, 8, 29. [CrossRef]

33. Hua, W.; Mukamel, S.; Luo, Y. Transient X-ray Absorption Spectral Fingerprints of the S1 Dark State in Uracil. J. Phys. Chem. Lett. 2019, 10, 7172-7178. [CrossRef]

34. Jonas, A.; Dammer, K.; Stiel, H.; Kanngiesser, B.; Sánchez-de-Armas, R.; Mantouvalou, I. Transient Sub-nanosecond Soft X-ray NEXAFS Spectroscopy on Organic Thin Films. Anal. Chem. 2020, 92, 15611-15615. [CrossRef]

35. Moulet, A.; Bertrand, J.B.; Klostermann, T.; Guggenmos, A.; Karpowicz, N.; Goulielmakis, E. Soft x-ray excitonics. Science 2017, 357, 1134-1137. [CrossRef] [PubMed]

36. Scholz, M.; Holch, F.; Sauer, C.; Wiessner, M.; Scholl, A.; Reinert, F. Core Hole-Electron Correlation in Coherently Coupled Molecules. Phys. Rev. Lett. 2013, 111, 048102. [CrossRef]

37. Ryland, E.S.; Lin, M.-F.; Verkamp, M.A.; Zhang, K.; Benke, K.; Carlson, M.; Vura-Weis, J. Tabletop Femtosecond M-edge X-ray Absorption Near-Edge Structure of FeTPPCl: Metalloporphyrin Photophysics from the Perspective of the Metal. J. Am. Chem. Soc. 2018, 140, 4691-4696. [CrossRef]

38. Kern, J.; Alonso-Mori, R.; Tran, R.; Hattne, J.; Gildea, R.J.; Echols, N.; Glöckner, C.; Hellmich, J.; Laksmono, H.; Sierra, R.G.; et al. Simultaneous Femtosecond X-ray Spectroscopy and Diffraction of Photosystem II at Room Temperature. Science 2013, 340, 491-495. [CrossRef]

39. Van Kuiken, B.E.; Huse, N.; Cho, H.; Strader, M.L.; Lynch, M.S.; Schoenlein, R.W.; Khalil, M. Probing the Electronic Structure of a Photoexcited Solar Cell Dye with Transient X-ray Absorption Spectroscopy. J. Phys. Chem. Lett. 2012, 3, 1695-1700. [CrossRef] [PubMed]

40. Hillyard, P.W.; Kuchibhatla, S.; Glover, T.E.; Hertlein, M.P.; Huse, N.; Nachimuthu, P.; Saraf, L.V.; Thevuthasan, S.; Gaffney, K.J. Atomic resolution mapping of the excited-state electronic structure of $\mathrm{Cu} 2 \mathrm{O}$ with time-resolved x-ray absorption spectroscopy. Phys. Rev. B 2009, 80, 125210. [CrossRef]

41. Kim, J.; Kim, K.H.; Oang, K.Y.; Lee, J.H.; Hong, K.; Cho, H.; Huse, N.; Schoenlein, R.W.; Kim, T.K.; Ihee, H. Tracking reaction dynamics in solution by pump-probe $\mathrm{X}$-ray absorption spectroscopy and X-ray liquidography (solution scattering). Chem. Commun. 2016, 52, 3734-3749. [CrossRef] [PubMed]

42. Kleine, C.; Ekimova, M.; Goldsztejn, G.; Raabe, S.; Strüber, C.; Ludwig, J.; Yarlagadda, S.; Eisebitt, S.; Vrakking, M.J.J.; Elsaesser, T.; et al. Soft X-ray Absorption Spectroscopy of Aqueous Solutions Using a Table-Top Femtosecond Soft X-ray Source. J. Phys. Chem. Lett. 2019, 10, 52-58. [CrossRef]

43. Buades, B.; Picon, A.; Berger, E.; Leon, I.; Di Palo, N.; Cousin, S.L.; Cocchi, C.; Pellegrin, E.; Martin, J.H.; Manas-Valero, S.; et al. Attosecond state-resolved carrier motion in quantum materials probed by soft x-ray XANES. Appl. Phys. Rev. 2021, 8, 011408. [CrossRef]

44. Jonas, A.; Staeck, S.; Kanngießer, B.; Stiel, H.; Mantouvalou, I. Laboratory quick near edge x-ray absorption fine structure spectroscopy in the soft $x$-ray range with $100 \mathrm{~Hz}$ frame rate using CMOS technology. Rev. Sci. Instrum. 2021, 92, 023102. [CrossRef]

45. Jonas, A.; Stiel, H.; Glöggler, L.; Dahm, D.; Dammer, K.; Kanngießer, B.; Mantouvalou, I. Towards Poisson noise limited optical pump soft X-ray probe NEXAFS spectroscopy using a laser-produced plasma source. Opt. Express 2019, $27,36524-36537$. [CrossRef] [PubMed]

46. Cordones, A.A.; Pemmaraju, C.D.; Lee, J.H.; Zegkinoglou, I.; Ragoussi, M.-E.; Himpsel, F.J.; de la Torre, G.; Schoenlein, R.W. Excited-State Charge Distribution of a Donor $-\pi$-Acceptor Zn Porphyrin Probed by N K-Edge Transient Absorption Spectroscopy. J. Phys. Chem. Lett. 2021, 12, 1182-1188. [CrossRef]

47. Urquhart, S.G.; Martinson, M.; Eger, S.; Murcia, V.; Ade, H.; Collins, B.A. Connecting Molecular Conformation to Aggregation in P3HT Using Near Edge X-ray Absorption Fine Structure Spectroscopy. J. Phys. Chem. C 2017, 121, 21720-21728. [CrossRef]

48. Davoli, I.; Marcelli, A.; Bianconi, A.; Tomellini, M.; Fanfoni, M. Multielectron configurations in the x-ray-absorption near-edge structure of $\mathrm{NiO}$ at the oxygen K threshold. Phys. Rev. B 1986, 33, 2979-2982. [CrossRef] [PubMed] 
49. Ikeno, H.; Tanaka, I.; Koyama, Y.; Mizoguchi, T.; Ogasawara, K. First-principles multielectron calculations of Ni L2,3 NEXAFS and ELNES for LiNiO2 and related compounds. Phys. Rev. B 2005, 72, 075123. [CrossRef]

50. Jonas, A.; Meurer, T.; Kanngießer, B.; Mantouvalou, I. Note: Reflection zone plates as highly resolving broadband optics for soft X-ray laboratory spectrometers. Rev. Sci. Instrum. 2018, 89, 026108. [CrossRef]

51. Finazzi, M.; Brookes, N.; De Groot, F. 2p3s3p, 2p3p3p, and 2p3s3s resonant Auger spectroscopy from NiO. Phys. Rev. B 1999, 59, 9933-9942. [CrossRef]

52. Stiel, H.; Braenzel, J.; Tuemmler, J.; Jonas, A.; Mantouvalou, I.; Erko, A.; Heilmann, A.; Moerbeck-Bock, M.; Schnuerer, M. Ultrafast NEXAFS Spectroscopy in the Lab Using Laser-Based Sources and Advanced X-Ray Optics; SPIE: Bellingham, WA, USA, 2021; Volume 11886.

53. Schick, D.; Borchert, M.; Braenzel, J.; Stiel, H.; Tümmler, J.; Bürgler, D.E.; Firsov, A.; von Korff Schmising, C.; Pfau, B.; Eisebitt, S. Laser-driven resonant magnetic soft-x-ray scattering for probing ultrafast antiferromagnetic and structural dynamics. Optica 2021, 8, 1237-1242. [CrossRef]

54. Mantouvalou, I.; Witte, K.; Grötzsch, D.; Neitzel, M.; Günther, S.; Baumann, J.; Jung, R.; Stiel, H.; Kanngießer, B.; Sandner, W. High average power, highly brilliant laser-produced plasma source for soft X-ray spectroscopy. Rev. Sci. Instrum. 2015, 86, 035116. [CrossRef]

55. Mantouvalou, I.; Jung, R.; Tuemmler, J.; Legall, H.; Bidu, T.; Stiel, H.; Malzer, W.; Kanngießer, B.; Sandner, W. Note: Study of extreme ultraviolet and soft $\mathrm{x}$-ray emission of metal targets produced by laser-plasma-interaction. Rev. Sci. Instrum. 2011, 82, 066103. [CrossRef]

56. Mantouvalou, I.; Witte, K.; Martyanov, W.; Jonas, A.; Grötzsch, D.; Streeck, C.; Löchel, H.; Rudolph, I.; Erko, A.; Stiel, H.; et al. Single shot near edge x-ray absorption fine structure spectroscopy in the laboratory. Appl. Phys. Lett. 2016, 108, 201106. [CrossRef]

57. Vogt, U.; Wilhein, T.; Stiel, H.; Legall, H. High resolution x-ray absorption spectroscopy using a laser plasma radiation source. Rev. Sci. Instrum. 2004, 75, 4606-4609. [CrossRef]

58. Probst, J.; Braig, C.; Erko, A. Flat Field Soft X-ray Spectrometry with Reflection Zone Plates on a Curved Substrate. Appl. Sci. 2020, 10, 7210. [CrossRef]

59. Hakkoum, H.; Tibermacine, T.; Sengouga, N.; Belahssen, O.; Ghougali, M.; Benhaya, A.; Moumen, A.; Comini, E. Effect of the source solution quantity on optical characteristics of $\mathrm{ZnO}$ and $\mathrm{NiO}$ thin films grown by spray pyrolysis for the design $\mathrm{NiO} / \mathrm{ZnO}$ photodetectors. Opt. Mater. 2020, 108, 110434. [CrossRef]

60. Gouterman, M.; Wagniere, G.H. Spectra of porphyrins Part II: Four orbital model. J. Mol. Spectr. 1963, 11, 108-127. [CrossRef]

61. Braenzel, J.; Pratsch, C.; Hilz, P.; Kreuzer, C.; Schnürer, M.; Stiel, H.; Sandner, W. Note: Thickness determination of freestanding ultra-thin foils using a table top laboratory extreme ultraviolet source. Rev. Sci. Instrum. 2013, 84, 3. [CrossRef]

62. Vladimir, V.; Shelkovnikov, A.I.P. Optical and Resonant Non-Linear Optical Properties of J-Aggregates of Pseudoisocyanine Derivatives in Thin Solid Films, 41st ed.; InTEch: London, UK, 2013; Volume 1.

63. Sosa, M.L.; Wong, C.Y. Revealing the evolving mixture of molecular aggregates during organic film formation using simulations of in situ absorbance. J. Chem. Phys. 2020, 153, 214902. [CrossRef]

64. Neese, F.; Wennmohs, F.; Becker, U.; Riplinger, C. The ORCA quantum chemistry program package. J. Chem. Phys. 2020, 152, 224108. [CrossRef] [PubMed]

65. Feng, T.; Heilmann, A.; Bock, M.; Ehrentraut, L.; Witting, T.; Yu, H.; Stiel, H.; Eisebitt, S.; Schnürer, M. 27 W 2.1 mm OPCPA system for coherent soft $\mathrm{X}$-ray generation operating at $10 \mathrm{kHz}$. Opt. Express 2020, 28, 8724-8733. [CrossRef]

66. Marberger, A.; Petrov, A.W.; Steiger, P.; Elsener, M.; Kröcher, O.; Nachtegaal, M.; Ferri, D. Time-resolved copper speciation during selective catalytic reduction of NO on Cu-SSZ-13. Nat. Catal. 2018, 1, 221-227. [CrossRef]

67. Ekimova, M.; Quevedo, W.; Faubel, M.; Wernet, P.; Nibbering, E.T.J. A liquid flatjet system for solution phase soft-x-ray spectroscopy. Struct. Dyn. 2015, 2, 054301. [CrossRef] [PubMed]

68. Grötzsch, D.; Streeck, C.; Nietzold, C.; Malzer, W.; Mantouvalou, I.; Nutsch, A.; Dietrich, P.; Unger, W.; Beckhoff, B.; Kanngießer, B. A sealable ultrathin window sample cell for the study of liquids by means of soft X-ray spectroscopy. Rev. Sci. Instrum. 2017, 88, 123112. [CrossRef] [PubMed] 